\title{
GABRIELA MISTRAL: AUTOEXÍLIO, DANÇAS DE RODA, RECADOS E EXPERIÊNCIAS POSTAS EM CIRCULAÇÃO COMO FORMA DE EDUCAÇÃO
}

\author{
Carola Gabriela Sepúlveda Vásquez*
}

\section{RESUMO}

Neste trabalho tenta-se compreender o autoexílio de Gabriela Mistral como uma experiência fundamental na sua vida, o que lhe permitiu criar movimentos compreendidos metaforicamente na figura de danças de roda. As rodas apresentam uma possibilidade de releitura, em termos simbólicos e políticos, da figura e da obra de Mistral, pois permitem pôr em tensão algumas das leituras oficiais que se fizeram delas. Compreendem-se as rodas como espaço de resistência, onde Mistral uniu diferentes vozes (alheias e próprias) para criar seus cantos e dançar nessa união com outros(as), estabelecendo diferentes conexões, por meio de suas viagens, interações, escrita de si e das mensagens como Recados que entregava na roda, as quais transmitiam suas experiências e enviavam convites para sentir, refletir e circular.

Palavras-chave: Gabriela Mistral, autoexílio, danças de roda, experiências, educação.

\footnotetext{
* Universidad Metropolitana de Ciencias de la Educación (UMCE), Santiago, Chile.
} 


\title{
GABRIELA MISTRAL: AUTOEXILIO, RONDAS, RECADOS Y EXPERIENCIAS PUESTAS EN CIRCULACIÓN COMO FORMA DE EDUCACIÓN
}

\section{RESUMEN}

En este trabajo tratamos de comprender el autoexilio de Gabriela Mistral como una experiencia fundamental en su vida y que le permitió crear movimientos que comprendemos metafóricamente bajo la figura de ronda. Las rondas presentan una posibilidad de relectura en términos simbólicos y políticos de la figura y obra de Mistral, pues permiten poner en tensión algunas de las lecturas oficiales que se hicieron de ellas. Comprenderemos las rondas como espacio de resistencia, donde Mistral unió diferentes voces (ajenas y propias) para crear sus cantos y danzar en esa unión con otros (as), estableciendo diferentes conexiones, por medio de sus viajes, interacciones, escrita de si y de sus mensajes como Recados que entregaba en la ronda, las cuales transmitían sus experiencias y enviaban invitaciones a sentir, reflexionar y circular.

Palabras clave: Gabriela Mistral, autoexilio, rondas, experiencias, educación.

\section{GABRIELA MISTRAL: SELF-EXILE, CIRCLE DANCES, NOTES AND EXPERIENCES PUT INTO CIRCULATION AS A FORM OF EDUCATION}

\begin{abstract}
In this work, we try to understand Gabriela Mistral's self-exile as a fundamental experience in her life, which allowed her to create movements understood metaphorically in the figure of circle dances. The circles appear as a possibility of reinterpreting, in symbolic and political terms, the figure and work developed by Mistral, once they allow to put in tension some of the official readings that were made of them. The circles are understood as a space of resistance, where Mistral joined different voices (foreign voices and her own) to create the songs and to be able to dance in this union with other people, establishing different connections, through her travels, interactions, writing of herself and from messages as notes that she delivered at the circles, which transmitted her experiences and also sent invitations to feel, to reflect and to circulate.
\end{abstract}

Keywords: Gabriela Mistral, self-exile, circle dances, experiences, education.

\section{GABRIELA MISTRAL: AUTO-EXIL, DANSES EN CERCLE, MESSAGES ET EXPÉRIENCES MIS EN CIRCULATION COMME FORME D'ÉDUCATION}

\section{RÉSUMÉ}

Ce travail tente de comprendre l'auto-exil de Gabriela Mistral comme une expérience fondamentale dans sa vie, ce qui lui a permis de créer des mouvements compris métaphoriquement dans la figure des danses circulaires. Les cercles offrent une possibilité de réinterpréter, en termes symboliques et politiques, la figure et l'œuvre de Mistral, car elles 
permettent de mettre en tension certaines des lectures officielles qui en ont été faites. Les cercles sont comprises comme un espace de résistance, où Mistral a rejoint différentes voix (des autres et propres) pour créer ses chansons et danser dans cette union avec les autres, établissant des connexions différentes, à travers de ses voyages, interactions, écriture de lui-même et de messages comme Notes qu'il a donné à les cercles, qui ont transmis ses expériences et envoyé des invitations à ressentir, réfléchir et circuler.

Mots-clés: Gabriela Mistral, auto-exil, danse en cercle, expériences, education. 


\section{INTRODUÇÃO}

"La bailarina ahora está danzando la danza del perder cuanto tenía. Deja caer todo lo que ella había, padres y hermanos, huertos y campiñas, el rumor de su río, los caminos, el cuento de su hogar, su propio rostro y su nombre, y los juegos de su infancia como quien deja todo lo que tuvo caer de cuello, de seno y de alma". Gabriela Mistral

Gabriela Mistral nasceu no Chile em 1889. Ela foi professora, escritora ${ }^{1} \mathrm{e}$ diplomata. Neste trabalho, procuro, compreender Mistral de uma forma rizomática, acreditando na proposta do historiador francês François Dosse, que, em seus estudos sobre história intelectual, tem incorporado esta visão. Para o autor, a forma rizomática poderia "ser sugestiva no plano biográfico porque reveste algumas implicações metodológicas que confortam a pluralização identitária. Qualquer ponto de um rizoma pode ser ligado com qualquer outro, o que induz uma predominância dos princípios de heterogeneidade e de conexão" (DOSSE, 2009, p. 407).

Proponho, ainda, inspirada em Dosse e Deleuze, entender este artigo como um Rizoma, onde "como em qualquer coisa, há linhas de articulação ou de segmentariedade, estratos, territorialidades; mas também linhas de fuga, movimentos de desterritorialização e de desestratificação" (DELEUZE; GUATTARI, 2004, p. 8). Por isso, minha proposta, é apresentar este texto recuperando também a figura da Roda, onde as escolhas teóricas e metodológicas procuram estimular leituras e que qualquer ponto do texto possa ser conectado com qualquer outro. Partindo dessa heterogeneidade que a escrita contém, pretendo que a mesma se espalhe, seguindo o conceito de Roda como rizoma, ou seja, um conceito que inclui ruptura, além de "alongar, prolongar, religar a linha de fuga, fazê-la variar, até produzir a linha mais abstrata e a mais sinuosa de $\mathrm{n}$

\footnotetext{
${ }^{1}$ Mistral recebeu o Prêmio Nobel de Literatura em 1945, quando residia no Brasil.
} 
dimensões, com direções quebradas" (DELEUZE; GUATTARI, 2004, p. 27).

Assim, o artigo pretende compreender o autoexílio de Gabriela Mistral como uma experiência fundamental na sua vida, o que lhe permitiu criar movimentos compreendidos metaforicamente na figura de danças de roda, entendidas como espaço de resistência, pois, possibilitaram que Mistral:

Resistisse a seu autoexílio, permitindo-lhe (se) escrever nessa experiência de transmissão de experiências.

Criasse movimentos e uma escrita em coletivo, que fugiu de numerosas fronteiras (espaciais, temporais e simbólicas), conectando pessoas, espaços e tempos.

Se comunicasse com sua comunidade imaginada da América Latina, pondo em circulação suas experiências como forma de educação, constituindo também uma forma de intervenção intelectual, onde a autora escreveu sobre assuntos como a defesa da paz, das liberdades e das democracias, valores com os quais se sentia comprometida. Além disso, se posicionou em relação às temáticas que afetavam o Chile e a América Latina, defendeu ideias e fez circular experiências, informações e modelos.

Mistral morou grande parte de sua vida fora de seu país natal, e suas viagens foram experiências bastante influentes na construção de sua subjetividade e sensibilidade. Para Mistral (1978), a viagem

\footnotetext{
da la costumbre del olvido. Nada penetra en nosotros sin desplazar algo: la imagen nueva se disputa con la que estaba adentro, moviéndose con desahogo de medusa en el agua; después la cubre como una alga suavemente, sin tragedia. Viajar es profesión del olvido. Para ser leal a las cosas que venimos a buscar, para que el ojo las reciba como al huésped, espaciosamente, no hay sino el arrollamiento de las otras (p. 20).
}

É relevante, também, não esquecer que as viagens representaram uma possibilidade de autoconhecimento em vários sentidos, pois permitem ao 
viajante se perguntar por múltiplas dimensões da vida:

El viaje aconsejará como el sueño enseña a algunos iluminados. Le señalará oficio, país y mujer. Le diría si es italiano y deberá aprender su Dante en Florencia, si platero y vivir unos años en fundición de Toledo. O si, sencillamente, es de su tierra, y no puede aprender nada sino moviéndose en la divina dulzura de lo suyo (MISTRAL, 1978, p. 20).

Foram as viagens que propiciaram a Mistral experimentar em muitos lugares essa forma de olhar diferente, isto é, o olhar daquele que vem de fora (GINZBURG, 2001). Elas lhe atribuíram autoridade e contribuíram, portanto, para o aumento de seu prestígio no exercício de seu trabalho². Além de lhe permitir a manutenção econômica, como diz Mistral no seu texto Carta a mi biógrafo, de 19343:

Acuérdense también de que la otra publicidad, la de mis viajes, me la acarrea la búsqueda del pan. Voy aquí y voy allá a dar clases (nadie vive de trescientas pesetas de una jubilación) y debo aceptar que los pueblos dispongan de mi como de persona llegada a ellos para servirlos (s.p.).

Mistral saiu do Chile em 1922, convidada pelo governo do México, para colaborar na Reforma Educativa proposta pela Revolução mexicana. Em um ambiente rico e cheio de reconhecimento, viveu experiências que marcaram sua vida. Trabalhou com José Vasconcelos ${ }^{4}$, com quem se identificou e teve trocas intelectuais que influenciaram fortemente suas intervenções. Nessa experiência,

\footnotetext{
2 Um texto que trabalha a importância da viagem no aumento da autoridade e reconhecimento para a mulher professora é A educação como problema, a América como destino: a experiência de Maria Guilhermina, de Carla Chamon e Luciano Mendes de Faria Filho (2007).

3 Este documento consiste num recorte do jornal que pertence ao acervo digital da Biblioteca Nacional de Chile, mas não apresenta os números de páginas.

4 José Vasconcelos (1882-1959). Político, filósofo, advogado e intelectual mexicano. Ele foi Ministro de Educação Pública de seu país entre os anos 1921 e 1924, lugar desde o qual liderou reformas que pretendiam unir simbolicamente a nação mexicana, utilizando o recurso da mestiçagem para conseguir o desenvolvimento cultural do país. Entre suas ações se incluem a organização da Universidad Nacional Autónoma de México (Unam), programas de educação popular, edição de livros e difusão da arte e da cultura.
} 
Mistral se aproximou de algumas ideias significativas para seu trabalho como intelectual, como, por exemplo, o conceito de educação pública como cruzada e a concepção de educação além do espaço escolar. Depois de sua experiência mexicana, a autora voltou ao país natal somente em visitas ocasionais. Mistral viveu seu "autoexílio" até sua morte em Nova York em 1957.

Quando Gabriela Mistral falava sobre sua estadia fora do Chile, usava a palavra "autoexílio" - segundo minha interpretação, para destacar que sua saída do país natal correspondia a uma escolha. O "autoexílio" deixou marcas profundas na vida e na produção de Mistral: influenciou as temáticas de suas obras, de suas memórias e de seus esquecimentos.

Edward Said (2003), crítico literário, dizia que

a vida do exilado anda segundo um calendário diferente e é menos sazonal e estabelecida do que a vida em casa. O exílio é a vida levada fora da ordem habitual. É nômade, descentrada, contrapontística, mas, assim que nos acostumamos a ela, sua força desestabilizadora entra em erupção novamente (p. 60).

Na linha argumentativa de Said, de uma vida levada fora da ordem habitual, tento compreender a vida de Mistral fora do Chile, onde me parece que, retomando como metáfora a bailarina, do poema citado na epígrafe, Mistral foi, muitas vezes, dançando e vivendo perdas, essas que se produzem ao se deixar o familiar e enfrentar as distâncias e as estranhezas que geram os deslocamentos.

Considero importante compreender o autoexílio de Mistral como uma experiência existencial, além de sua definição no âmbito jurídico, isso porque, lendo algumas de suas narrativas, posso identificar que ela viveu, desde muito, cedo uma relação complexa com seu país natal, chegando a sentir, em muitas ocasiões, o desterro na sua própria terra5. Assim, entendo esses movimentos de Mistral como fugas geográficas e simbólicas. Nesse sentido, considero

\footnotetext{
${ }^{5}$ Para mais detalhes, conferir Scarpa (1977).
} 
interessantes as reflexões de Edward Said (2004) sobre sentir-se fora do lugar, em um estranhamento que faz ruído, algo que posso reconhecer em muitas das narrativas mistralianas, em que a autora dizia sentir-se estranha e diferente ao comparar-se com outros(as), sendo provavelmente esse um dos custos simbólicos que precisou enfrentar pela transgressão de algumas normas sociais, pelo fato de ser considerada diferente para sua condição de mulher, provinciana e pobre, sobretudo em uma sociedade e em uma época marcadas pelas exclusões socioeconômicas e de gênero, entre outras (MANZANO, 2008, p. 10-16; PIZARRO, 2008, p. 24).

Muitos trabalhos biográficos sobre Mistral a abordam como uma pessoa fora dos cânones, chegando inclusive a ser considerada por alguns como anômala:

\footnotetext{
Mistral tuvo una existencia anómala que quebraba los parámetros dictaminados para las mujeres de su época. Aunque formó parte de la diplomacia chilena, que permitió parte de su desplazamiento, en rigor no perteneció a la carrera diplomática, lo cual evidentemente la puso en un lugar si no difícil, al menos incómodo.

Como poeta tuvo diálogos importantes con notables figuras intelectuales y literarias de su tiempo, pero también desacuerdos, tensiones y hasta lesiones provenientes del campo cultural (ELTIT, 2008, p. 30).
}

Esses movimentos geográficos e simbólicos que se produzem com o exílio significaram mudanças nas formas em que Gabriela Mistral se percebia. Nesse sentido, retomo as leituras de Tzevan Todorov sobre seu próprio exílio, pois elas me permitem compreender as experiências e a escrita de Mistral. Todorov (2008) define seu estado da seguinte forma:

Mi estado actual no corresponde, pues, a la 'desculturación', ni siquiera a la 'aculturación', sino más bien a lo que podría llamarse la transculturación [ênfase no original], la adquisición de un nuevo código sin pérdida del antiguo. Así, vivo en un espacio singular, a la vez fuera y dentro: como extranjero en 'mi casa' (en Sofía), en mi casa 'en el 
extranjero' (en París) (p. 27).

Foi nesse exílio, descrito por Todorov como espaço singular, em que se está dentro e fora de um país ao mesmo tempo, que Mistral viveu muitas experiências e aprendizagens, acompanhadas da dor da solidão e do estranhamento, que surgem do fato de estar em um lugar fora do familiar. É relevante observar que o conceito familiar se desloca e é colocado em tensão; no entanto, esse olhar para os outros também possibilita olhar para o nosso. Soledad Falabella (1997), em seu artigo Desierto: território, desplazamiento y nostalgia en Poema de Chile de Gabriela Mistral, indica que o deslocamento físico teria como resultado o deslocamento do ser. Com isso, deixaríamos de ser parte de uma totalidade para converter-nos em observadores externos, individuais:

Nace así un sujeto desplazado y nostálgico, cuya percepción del origen viene acompañada de nuevas sensaciones de extrañeza y de pérdida [ênfase no original]:la imagen del origen difiere del recuerdo de lo que fue el origen, el cual ya no se puede recuperar (FALABELLA, 1997, p. 81-82).

Essa estranheza de deixar o país natal e a intensidade com que ela é vivida foi algo que Todorov (2008) relatou desde sua própria experiência como intelectual no exílio:

El hombre desarraigado, arrancado de su marco, de su medio, de su país, sufre al principio, pues es más agradable vivir entre los suyos. Sin embargo, puede sacar provecho de su experiencia. Aprende a dejar de confundir lo real con lo ideal, la cultura con la naturaleza. No por conducirse de modo diferente dejan estos individuos de ser humanos. A veces se encierra en el resentimiento, nacido del desprecio o de la hostilidad de sus huéspedes. Pero si logra superarlo, descubre la curiosidad y aprende la tolerancia. Su presencia entre los 'autóctonos' ejerce a su vez un efecto desarraigante: al perturbar sus costumbres, al desconcertar por su comportamiento y sus juicios, puede ayudar a algunos de entre ellos a adentrarse en esta misma vía de desapego hacia lo convenido, una vía de interrogación y de asombro (p. 29). 
Segundo Todorov, o movimento que provoca o exílio permite ir além do desenraizamento geográfico e ensaiar "miradas desarraigadas" (2008, p. 29), olhares diferentes e nômades, leitura que permite analisar as reflexões e os questionamentos que sensibilizaram Mistral. Considerando o exílio como experiência de vida (SAID, 2004), concordamos que

\begin{abstract}
é terrível de experienciar. Ele é uma fratura incurável entre um ser humano e um lugar natal, entre o eu e seu verdadeiro lar: sua tristeza essencial jamais pode ser superada. E, embora seja verdade que a literatura e a história contêm episódios heroicos, românticos, gloriosos e até triunfais da vida de um exiliado, eles não são mais do que esforços para superar a dor mutiladora da separação. As realizações do exílio são permanentemente minadas pela perda de algo deixado para trás para sempre (SAID, 2003, p. 46).
\end{abstract}

Assim, vejo Mistral com marcas dessa fratura que origina o exílio, criando movimentos, o que entenderei como danças de roda que marcam sua escrita como resistências à dor da perda, essa, que segundo Said, se produz ao saber que abandonamos algo para sempre. Mistral (2010b) tem um poema intitulado La extranjera, em que ela nos aproxima de sua própria vida:

Vivirá entre nosotros ochenta años, /pero siempre será como si llega, / hablando lengua que jadea y gime/ y que le entienden solo bestezuelas./ $\mathrm{Y}$ va a morirse en medio de nosotros,/ en una noche en la que más padezca,/ con solo su destino por almohada,/ de una muerte callada y extranjera [ênfase no original] (p. 283).

A continuação apresento na figura 1, a fotografia do passaporte de Gabriela Mistral. Ela é interessante, pois representa simbolicamente os movimentos da autora nas viagens. Foram esses movimentos que a levaram a viver no autoexílio por mais de três décadas.

As fotografias incluídas neste artigo são analisadas seguindo o modelo proposto pela professora Olga Von Simson em seu texto (no prelo), mas com algumas adaptações para adequá-lo às necessidades deste texto. Assim, se 
apresenta a fotografia acompanhada de um quadro (Quadro 1), que inclui dados sobre a fonte, além da interpretação desta.

Figura 1 - Passaporte diplomático de Gabriela Mistral.

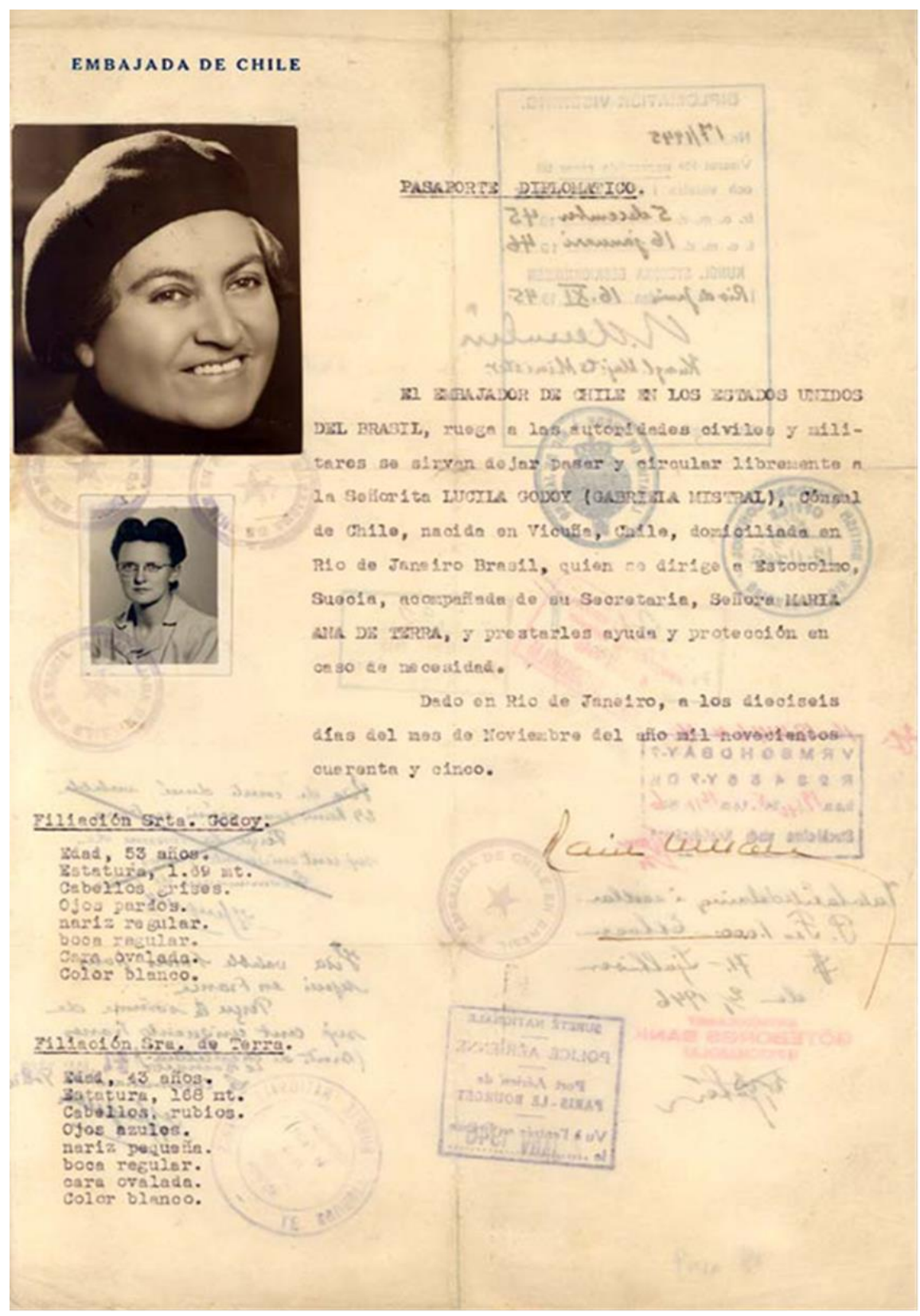


Fonte: Cervantes Virtual ${ }^{6}$

Quadro 1 - Dados do passaporte diplomático de Gabriela Mistral.

\begin{tabular}{|c|c|c|c|}
\hline DATA & LOCAL & CARACTERIZAÇÃO & OBSERVAÇÕES \\
\hline 1945 & $\begin{array}{l}\text { Emitido pela } \\
\text { Embaixada do Chile }\end{array}$ & $\begin{array}{l}\text { No passaporte, o } \\
\text { Embaixador pede às } \\
\text { autoridades civis } \mathrm{e} \\
\text { militares “dejar pasar y } \\
\text { circular libremente" a } \\
\text { intelectual, o que ela } \\
\text { efetivamente praticou. }\end{array}$ & \begin{tabular}{lr}
\multicolumn{3}{l}{ No documento estão } \\
inclusos os dois \\
nomes da autora (o \\
civil e \\
pseudônimo).
\end{tabular} \\
\hline
\end{tabular}

Fonte: Elaborado pela autora.

\section{DANÇAS DE RODA}

Neste trabalho, recupero e ressignifico a figura da roda e o gênero das danças de roda, amplamente representativo do trabalho de Mistral, para interpretar o processo criativo e de intervenção da intelectual durante o período em que ela morou no autoexílio.

Retomar o conceito de roda significa um desafio e uma tentativa de ressignificação da imagem e da obra de Mistral, construídas oficialmente no Chile, processo intensificado, principalmente, a partir da Ditadura de Augusto Pinochet (1973-1990)7, que tentou reduzir e domesticar Gabriela Mistral, fazendo

${ }^{6}$ Disponível em:

http://www.cervantesvirtual.com/bib_autor/gabrielamistral/pcuartonivel.jsp?conten=imagene $\mathrm{s} \&$ pagina $=$ imagenes3.jsp\&fqstr $=1 \& q$ Pagina $=0 \& q I m a g e n=12$. Acesso em 11 mai. 2014.

7 Soledad Falabella (2003, p. 20-25) analisa algumas das apropriações da figura de Mistral por parte da Ditadura de Pinochet, destacando, por exemplo: a mudança de nome da Editorial Estatal, o uso da fotografia na nota de 5000 pesos chilenos, o uso do nome de Mistral para a Universidade Privada mais conservadora do país e para o prédio onde se organizavam as estratégias militares. 
uma leitura hegemônica da autora como mãe e como professora submissa e apagando tudo aquilo que não contribuísse com essa leitura.

Olga Grandón (2004), a partir da leitura de Soledad Bianchi, indica que o processo de efervescência da crítica mistraliana foi mais evidente a partir de 1977, tendo em vista que o governo tinha a intenção de invisibilizar a figura de Pablo Neruda, escritor, militante comunista e diplomático chileno ${ }^{8}$ que recebeu o Prêmio Nobel de Literatura em 19719. Enfim, foi dessa maneira que a Ditadura de Pinochet tentou apagar a ameaça que significavam as letras e a visibilidade política internacional de Neruda ${ }^{10}$.

Voltando à figura da roda, ela pode ser recuperada e lida de uma forma diferente das leituras oficiais, contribuindo para uma maior compreensão da obra de Mistral. Cecilia García Huidobro (2008) reconhece que a figura e a obra de Mistral têm uma importância significativa na cultura latino-americana, mesmo que, muitas vezes, tenhamos dificuldade em reconhecê-la. Para a autora:

La impresionante obra de Gabriela Mistral va mucho más allá de la
imagen estereotipada de maestra rural que hace rondas infantiles
[ênfase adicionada]. Su complejidad, profundidad filosófica, rigor
intelectual y vuelo creativo la convierten en una de las columnas sobre
las que se sostiene la cultura americana. Sin embargo, nos ha costado
dimensionar la monumentalidad de su imponente figura mestiza,
siendo la prueba más elocuente el otorgamiento del Premio Nobel,
antes que el Premio Nacional de Literatura (HUIDOBRO, 2008, p. 25).

Assim, as rodas apresentam uma possibilidade interessante de releitura em termos simbólicos e políticos, por isso as reconheço como um espaço de resistência, onde Mistral uniria suas diferentes vozes (alheias e próprias) para

\footnotetext{
8 Em 1970, Neruda foi nomeado candidato à Presidência da República do Chile, mas renunciou a sua candidatura para apoiar Salvador Allende.

9 Atualmente, junto com Mistral, são os únicos chilenos homenageados com esse Prêmio.

10 A morte do escritor em 1973, 12 dias depois do golpe de Estado no Chile, continua sendo um tema polêmico e ainda hoje se discute no Chile se caberia alguma responsabilidade direta à Ditadura.
} 
criar seus cantos $^{11}$ e dançar nessa união com outros(as), estabelecendo diferentes conexões, por meio de suas viagens, de suas interações e de sua escrita. Nelas, Mistral teve outras formas de compreensão do tempo (além do tempo medido pelo relógio) e do espaço, que conectava memórias, experiências e desejos. Nelas, se conectam, também, múltiplas histórias locais, nacionais e internacionais, que se tornaram convites para sentir, refletir e circular. As formas de criação e de relacionamento de Mistral podem ter sido influenciadas pelas experiências de educação informal e não formal que ela teve ao longo de sua vida, como, por exemplo, sua experiência no México, já mencionada aqui. É comum encontrar em suas narrativas falas sobre a exclusão de alguns círculos de influência em diferentes instituições ou grupos. Acredito que essas experiências tenham influenciado Mistral a criar novos círculos e novas formas de circular, as quais procuro entender utilizando a figura da roda. A esse respeito, afirma Valdivia de Kirinus (1999) que "a metáfora da roda sugere o movimento em que prevalece o saber eclético que dinamiza saberes. Este saber que circula apresenta-se mais solidário e menos competitivo" (p. 279).

Para Mauricio Ostria González (2010), "las rondas configuran una voz plural (un coro infantil) y un movimiento solidario” (p. 657). É desse modo que entendo as rodas mistralianas, com marcas de coletividade e solidariedade que caracterizam sua escrita e a forma como compreende o conceito de educação.

A ideia de roda nos remete à figura do círculo, o que, segundo a leitura de Maria Rita Oriolo de Almeida (2011),

simboliza a relação do homem com a natureza e independente se na religião, nas artes ou na psicologia, representa a unidade e a totalidade. Tem o centro como organizador e ponto de conexões, não tem ponta, primeiro ou último lugar; todos olham para o centro, veem-se, estabelecem contato, sendo este de estranhamento, de alteridade, de

${ }^{11}$ Destaco a palavra, pois em numerosos momentos, Gabriela Mistral utilizou a figura do canto em seus escritos como metáfora de seu próprio trabalho. 
equidade, ou ainda envolvendo o sentimento de pertencimento (p. 34).

Essa leitura me permite entender que nesse círculo da roda se unem vários participantes, o que converte os cantos mistralianos em um coro polifônico. Desde a análise literária, também é possível reconhecer a ideia de união presente nas rodas mistralianas. Sandra Trabucco Valenzuela (1992) indica que "a repetição de palavras e o uso reiterado do conectivo 'y' fazem com que formalmente a estrofe também 'dê as mãos', unindo-se oração a oração e integrando o movimento giratório a través da repetição" (p. 137). União que estaria nas palavras, na forma de construção e nas mensagens que Mistral (2010c, p. 124) entregava na roda:

Dame la mano y danzaremos;! dame la mano y me amarás./ Como una sola flor seremos,/ como una flor, y nada más.../ El mismo verso cantaremos,/al mismo paso bailarás./ Como una espiga ondularemos,/ Como una espiga, y nada más.

Segundo Trabucco Valenzuela (1992), as Rodas mistralianas "podem ser interpretadas como cânticos à fecundidade da Terra ou da Mulher. O espaço para realização dos cânticos revela-se como a Gea americana, onde se desenvolve a miscigenação das culturas indo-americanas e a hispânica" (p. 190). Seguindo essa leitura, entendo esse espaço como lugar de fecundidade, produto da amálgama de experiências.

Quando pensei em fazer uma leitura diferente da roda, comecei a (re)ler essas mesmas rodas que há muitos anos circulavam no Chile, país de origem de Mistral, incluindo, também, algumas publicadas recentemente, que foram conhecidas a partir da nova doação do arquivo da escritora em 200712. Foi nesses mesmos textos que Mistral trabalhou certas características que ela reconhecia na roda, coincidindo com algumas que já comentamos anteriormente. A partir disso,

$12 \mathrm{O}$ arquivo foi doado por Doris Atkinson, sobrinha de Doris Dana (última companheira de Mistral), que, ao morrer, deixou-a como testamentária. 
proponho compreender as rodas mistralianas como representações de resistência, conexão, escrita de si, trabalho coletivo e ideia de ciclo e espaço, de amálgama e transmissão de experiências.

Um dos elementos que permitem observar a ideia de resistência é representado pelo movimento permanente da dança com a presença dos cantos, expresso nas letras: "Danzan arriba sin descanso/ en el cielo claro o tempestad./ El canto no se les escucha/ pero no cesan de cantar" (MISTRAL, 2011a, p. 31).

A resistência é um convite a assumir uma postura ativa e de empoderamento: "canten, canten para que se acuerde/ la noche y el día./ La huerta se volvió muda/ y está muerta aunque esté viva./ Cantar más alto, cobrarlo" (MISTRAL, 2011b, p. 24).

Por outro lado, essas rodas representam uma possibilidade de conexão em diferentes sentidos, possibilitam as fugas de numerosas fronteiras (geográficas e simbólicas), algo que Mistral (2011c, p. 21) escreve de forma poética: "Quebrad esa nuez del mundo/ que rota la dejaréis./ Abrid el cielo cantando/ y en cielo abierto dancéis”.

Sobre as rodas, podemos dizer também que representam um espaço onde Mistral (2011c, p. 21) se escreve a si mesma no autoexílio e cria uma resistência a ele: "Bailad el cuerpo y el alma/ echando al ruedo lo que tenéis, / y perdéos, baila que baila,/ que bailando os ganaréis".

Por meio das rodas, ela conecta diferentes vozes e memórias, inclusive as recuperadas de outras pessoas. Nas narrativas mistralianas, encontram-se, por exemplo, memórias que pertenceram às meninas que ela conheceu e a algumas de suas antigas alunas: "En mi falda yo me tengo/ una cosa de llevar:/ una niña que no puede/ responder ni preguntar” (MISTRAL, 2011d, p. 23).

A figura de mãos dadas que aparece frequentemente nas rodas mistralianas representa a união e o trabalho coletivo. É interessante observar como em muitas dessas rodas aparecem as mãos de mulheres, o que permitiria fazer também uma leitura de gênero: "Dame la mano, Francisca/ dame la tuya, 
Lucía,/ que la ronda no se puede/ hacer de manos caídas" (MISTRAL, 2011e, p. 25). A ideia do trabalho coletivo também aparece em uma roda intitulada Convite $^{13}$, em que a roda surge como um movimento de liberdade e de resistência: "Bailad las cuatro estaciones/ los amigos y el rondel./ Cabellos y brazos al viento/ bailad como que voléis" (2011c, p. 20).

Reconheço a ideia de ciclo nas rodas, pois em numerosas ocasiões a escrita mistraliana apresenta figuras como o círculo, a natureza, a vida e a morte, e todas dariam conta de processos e transformações: "cogiendo nuestras manos/ al centro como el sol/ fue bailando la muerte/ y la resurrección" (MISTRAL, 2011f, p. 19). Exemplo disso foi sua escrita sobre a natureza como recurso para mostrar a ideia de circularidade, pois

os movimentos da natureza são cíclicos como o nascer do sol, da lua, das estações do ano; a lógica da vida: nascer, desenvolver e morrer. Encontra-se em diversas religiões e mitos, está presente nos rituais de passagens, nas celebrações e em orações (ALMEIDA, 2011, p. 35).

Proponho pensar essas rodas como espaços de amálgama e transmissão de experiências, entendidas em sentido benjaminiano (BENJAMIN, 1994). Parece-me interessante observar que em muitas rodas chilenas é comum a presença de um anel como objeto de intercâmbio, que circula como símbolo de riqueza. Penso nesse anel em sentido mais amplo, além do objeto econômico, representando metaforicamente a riqueza das experiências, a que circula, se compartilha e em alguns casos se transforma em herança: "crece el ruedo y el anillo/ y la sangre y el contento/ por llegar a la otra ronda/ que está lejos como um cuento" (MISTRAL, 2011g, p. 34).

Nessas rodas, Mistral se conectou, fugiu de normas e se movimentou fora do lugar, pois é na roda que "todo es alto y todo vuela,/ los brazos, trenzas y sentidos" (MISTRAL, 2011h, p. 22). Com isso, ela construiu resistências em sua

13 O título é linguisticamente interessante, pois a palavra existe tanto em espanhol, quanto em português, as duas línguas que Mistral pretendia aproximar. 
escrita; em decorrência, alguns espaços de poder no Chile representaram sua figura e obra como ameaçante e, num exercício de exclusão, mutilaram-nas e apagaram-nas. Vale lembrar que a própria Mistral (2011g) já dizia que a roda era um perigo: "La rueda crece que asusta,/ toca mar y toca monte" (p. 34).

A continuação apresento na figura 2, a fotografia de um Caderno de Gabriela Mistral, acompanhado de um quadro (Quadro 2) que inclui dados sobre a fonte, além da interpretação desta. Destaco o caderno, pois inclui um desenho de pessoas dançando de mãos dadas, como se fosse uma roda, figura que recuperamos nas análises deste artigo.

Figura 2 - Caderno de Gabriela Mistral.

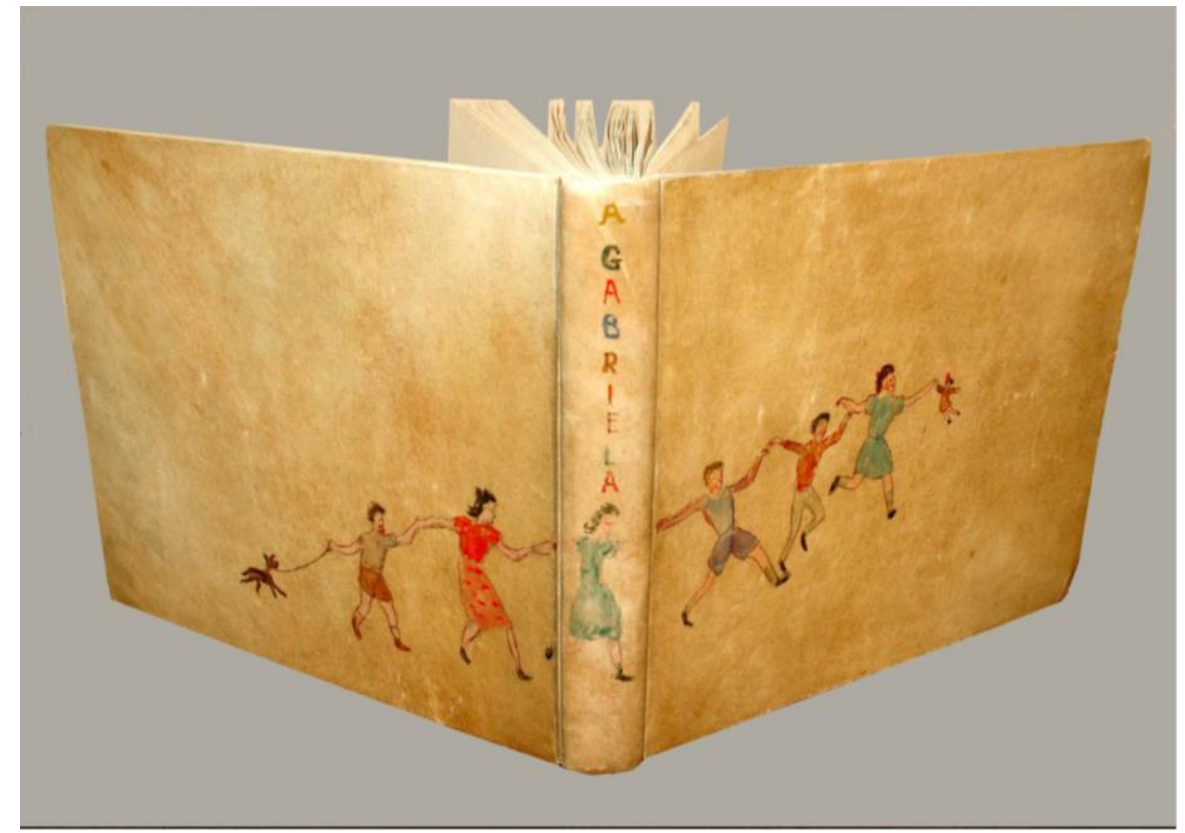

Fonte: Sala Mistral. ${ }^{14}$

14 Disponível em:

http://salamistral.salasvirtuales.cl/Upload/SGoooo647.pdf. Acesso em 11 mai. 2014. 
Quadro 2 - Dados do caderno.

\begin{tabular}{|l|l|l|}
\hline DATA & LOCAL & \multicolumn{1}{c|}{ CARACTERIZAÇÃO } \\
\hline $\begin{array}{l}\text { Sem } \\
\text { data }\end{array}$ & $\begin{array}{l}\text { Sem } \\
\text { local }\end{array}$ & $\begin{array}{l}\text { A imagem corresponde a um caderno que pertenceu a Mistral, um dos } \\
\text { objetos que chegou ao Chile com o legado doado em 2007. }\end{array}$ \\
\hline
\end{tabular}

Fonte: elaborado pela autora.

\section{RECADOS E EXPERIÊNCIAS POSTAS EM CIRCULAÇÃO COMO FORMA DE EDUCAÇÃO}

Em 1938, Gabriela Mistral (2010d) escreveu um texto intitulado Como escribo, em que falou de suas preferências, de seus gostos e suas emoções no processo da escrita. Leio, ali, a ideia de liberdade, que representa para ela o ato da escrita, algo que reconhecemos, por exemplo, quando fala da eleição de seus espaços de trabalho:

Yo escribo sobre mis rodillas y la mesa escritorio nunca me sirvió de nada, ni en Chile, ni en París, ni en Lisboa.

Escribo de mañana o de noche, y la tarde no me ha dado nunca inspiración, sin que yo entienda la razón de su esterilidad o de su mala gana para mí...

Creo no haber hecho jamás un verso en cuarto cerrado ni en cuarto cuya ventana diese un horrible muro de casa; siempre me afirmo en un pedazo de cielo, que Chile me dio azul y Europa me ha borroneado. Mejor se ponen mis humores si afirmo mis ojos viejos en una masa de árboles. (p. 588)

A necessidade de espaço aberto (para seu olhar e para sua alma) pode ser interpretada em Mistral (2010d) como a procura de liberdade que motivava seus movimentos, entendidos como deslocamentos em vários sentidos: "Me gusta escribir em cuarto pulcro, aunque soy persona harto desordenada. El orden parece regalarme espacio, y este apetito de espacio lo tienen mi vista y mi alma” (p. 589). 
Ela reconheceu as marcas que as viagens pelo mundo lhe deixaram, especialmente quando põe ênfase em sua condição de desterrada voluntária e de criatura vagabunda:

Mientras fui criatura estable [ênfase adicionada] de mi raza y mi país, escribí lo que veía o tenía muy inmediato, sobre la carne caliente del asunto. Desde que soy criatura vagabunda, desterrada voluntaria, parece que no escribo sino en medio de un vaho de fantasmas. La tierra de América y la gente mía, viva o muerta, se me han vuelto un cortejo melancólico pero muy fiel, que más que envolverme, me forra y me oprime y rara vez me deja ver el paisaje y la gente extranjeros (MISTRAL, 2010d, p. 588-589).

Portanto, escrever tornou-se uma atividade central na vida de Mistral, pois foi na escrita que ela amalgamou experiências e construiu resistências. Nesse contexto, minha leitura pretende retomar as características que, anteriormente, identifiquei na roda para analisar a escrita de Mistral durante o autoexílio e considerar a roda como uma resistência ${ }^{15}$, pois: 1) Possibilitou a Mistral resistir a seu autoexílio, permitindo-lhe (se) escrever nessa experiência de transmissão de experiências. 2) Propiciou os movimentos e a construção de uma escrita em coletivo, que fugiu de numerosas fronteiras (espaciais, temporais e simbólicas), conectando pessoas, espaços e tempos. 3) Permitiu que Mistral se comunicasse, durante seu autoexílio, com a comunidade imaginada da América Latina, pondo em circulação suas experiências como forma de educação.

Pensar a escrita e os relacionamentos de Mistral em forma de roda me permite acompanhar seus movimentos e suas fugas. Seguindo as reflexões de Deleuze e Guattari (2004), é possível imaginar essa roda como um mapa que "é aberto, é conectável em todas as suas dimensões, desmontável, invertível, susceptível de receber modificações constantemente.... Pode-se desenhá-lo numa parede, concebê-lo como uma obra de arte, construí-lo como uma ação política

15 Foi um grande aporte, para a compreensão da roda como forma de resistência na obra de Mistral, a leitura do trabalho A capoeira, arte de resistência e estética da potência, em que Camille Dumoulié (2007) analisa a roda de capoeira. 
ou como uma meditação" (p. 29).

Sinto que a obra de Mistral pode ser pensada, assim, como obra de arte, ação política e reflexão sobre o que acontecia no Chile e no mundo e entendo Mistral como uma bailarina de uma roda desterritorializada, pois "a dança, como música e poesia, ritmo e silêncio pleno, é, antes, uma desterritorialização dos dedos e pés cantantes, dedos e pés que são, na sua multiplicidade rizomática, o $\mathrm{CsO}^{16}$ do bailarino" (LINS, 2007, p. 88). Em cada roda, Mistral foi dançando em outros tempos e em outras geografias, criando novos movimentos e cantos que se amalgamaram em sua escrita, onde tudo se assemelha a movimento, música e mistura:

pode-se talvez dizer que nunca se dança nem em silêncio, nem com ou sobre [ênfase no original] a música tocada exteriormente, ao vivo ou gravada. Dança-se, sobremaneira, a partir e sob a impulsão e a pulsão de uma trama musical sempre nova, híbrida e evanescente (LINS, 2007, p. 90).

Considero importante entender a escrita de Mistral como um tipo de intervenção intelectual, em que ela própria reconhecia seu trabalho como missão. Desse modo, é pertinente retomar o conceito de missão de Sevcenko. Ele assim propõe: "todo escritor possui uma espécie de liberdade condicional de criação, uma vez que os seus temas, motivos, valores, normas e revoltas são fornecidos ou sugeridos pela sua sociedade e seu tempo - e é destes que eles falam" (1983, p. 20). Seguindo essa leitura, reconheço alguns dos compromissos de Mistral como intelectual com o Governo do Presidente Pedro Aguirre Cerda (1938 e 1941), com quem compartilhou valores.

Esse sentido de missão influenciou as temáticas de seus Recados, gênero particular da escrita mistraliana. Eles são textos em prosa e em verso, publicados entre 1919 e 1952, que tinham por títulos: Encargos, Mensagens, Recados,

${ }^{16} \mathrm{O}$ autor usa a sigla CsO para dar conta da figura do corpo sem órgãos, criada por Deleuze e Guattari. 
Comentários, Chamados, Palavras, Falas; ou, simplesmente, iniciam-se com expressões como: “Algo sobre...”, “Sobre...”, "Resposta a...”, “Carta a...”. Nos Recados, Mistral critica, parabeniza, adverte e entrega tarefas ao leitor, sempre em um tom íntimo e cheio de emoção: familiar, elogioso ou, às vezes, de censura (GRANDÓN, 2009).

Mistral (2010e) escreveu um texto intitulado Recados, onde definia o significado do gênero ao interior de sua obra. Sobre eles, dizia:

Las cartas que van para muy lejos y que se escriben cada tres o cinco años suelen aventar lo demasiado temporal- la semana, el año-y lo demasiado menudo-el natalicio, el año nuevo, el cambio de casa-. Y cuando, además, se las escribe sobre el rescoldo de una poesía, sintiendo todavía en el aire el revoloteo de un ritmo solo a medias roto y algunas rimas de esas que llamé entremetidas, en tal caso, la carta se vuelve esta cosa juguetona, tirada aquí y allá por el verso y por la prosa que se la disputan.

Por otra parte, la persona nacional con quien se vivió (personas son siempre para mí los países), a cada rato se pone delante del destinatario y a trechos lo desplaza. Un paisaje de huertos o de caña o de cafetal, tapa de un golpe la cara del amigo al que sonreíamos; un cerro suele cubrir la casa que estábamos mirando y por cuya puerta la carta va a entrar llevando su manojo de noticias.

Me ha pasado esto muchas veces. No doy por novedad tales caprichos o jugarretas: otros lo han hecho y, con más pudor que yo, se las guardaron. Yo las dejo en los suburbios del libro, fuora dei muri [ênfase no original], como corresponde a su clase un poco plebeya o tercerona. Las incorporo por una razón atrabiliaria, es decir, por una loca razón, como son las razones de las mujeres: al cabo, estos Recados llevan el tono más mío, el más frecuente, mi dejo rural en el que he vivido y en el que me voy a morir (p. 334).

Os Recados mistralianos que circularam durante seu autoexílio não são considerados neste trabalho como uma escrita de viagem ${ }^{17}$, na definição tradicional do gênero, pois me parece que Mistral não tem como objetivo ou eixo organizador retratar a experiência de suas diferentes viagens pelos diferentes

${ }_{17}$ Para mais informações sobre a escrita de viagens, conferir Peregrinas de outrora, viajantes latinoamericanas no século XIX, de Stella Maris Scatena Franco (2008). 
países, fazendo, por exemplo, comparações com seu país natal. Por isso, considero os Recados como uma escrita de viagem na roda, em que Mistral faz diálogo com as inúmeras mãos e notas que formam seu canto. E eles são, também, uma forma de comunicação que a autora utilizou para se comunicar com uma comunidade imaginada na América Latina, transmitindo experiências e educando.

A ideia de comunidade imaginada, elaborada por Benedict Anderson (2008), me permite compreender como Mistral pensou a América Latina e construiu uma escrita como se pensasse a americanidade com os (as) próprios (as) americanos (as). O objetivo era unir essa comunidade imaginada, por meio dos Recados, pois eles foram uma maneira de educar, pensada em uma relação com os projetos com que Mistral dialogava.

No texto aqui citado sobre os Recados, a autora afirma que ele é o gênero que inclui o seu tom mais íntimo e o mais frequente. Ele contém a herança rural que a autora viveu e que a acompanhou até sua morte. Os Recados incluem, também, as loucas razões que, segundo ela, caracterizariam as mulheres. Estes dois elementos, sexo-gênero e ruralidade, são significativos nesse tipo de escrita e se apresentam nas temáticas, no tipo de construção e nas marcas de oralidade dos textos mistralianos.

Segundo Grandón (2004), os Recados formam parte da prosa poética de Gabriela Mistral e são uma

forma híbrida como género literario, permite una mayor libertad de expresión a un proceso de escritura e identidad, que podemos catalogar de plural y en desplazamiento, tomando este último término en el sentido de 'viraje' de la significación que la metonímia demuestra y que desde su aparición en Freud, se presenta como el medio en que el inconsciente más apropiado para burlar la censura (Lacan, 1991: 196). Y así, la misma expresión (plano de lo formal) de los textos posee tensiones que, desde la perspectiva del lenguaje, también comprometen conflictivamente las dimensiones estilísticas y retóricas del discurso, tanto en su aspecto manifiesto como latente, tornándolo ambivalente (p. 11). 
Mistral falou em seus Recados sobre assuntos como a defesa da paz, das liberdades e das democracias. Além disso, se posicionou em relação a temáticas que afetavam também a América e o Chile no plano nacional, defendeu algumas ideias e fez circular informações e modelos.

Alfredo Bosi (2002), ao mencionar a importância dos valores no compromisso das pessoas que intervêm socialmente, dizia que

o homem de ação, o educador ou o político que interfere diretamente na trama social, julgando-a e, não raro, pelejando para alterá-la, só o faz enquanto é movido por valores. Estes, por seu turno, repelem e combatem os antivalores respectivos. $O$ valor é objeto da intencionalidade da vontade, é a força propulsora das suas ações. $\mathrm{O}$ valor está no fim da ação, como seu objetivo; e está no começo dela enquanto é sua motivação (p. 120).

Por concordar com essa leitura e entender que esse tipo de motivação teria inspirado muitas das escolhas de Mistral, de seus movimentos geográficos e simbólicos, posso reconhecer esse compromisso nas narrativas da autora, por exemplo, quando falava sobre seu trabalho, servindo ao Chile fora de seu território nacional:

Se ha dicho que yo no vuelvo a Chile. No es efectivo, señor, yo comprendo que tengo el deber de servir a Chile; pero tengo certidumbre de que le sirvo tanto o más, fuera que dentro del país. No hay una nación sudamericana que haga menos por su propaganda en el exterior. No le importa, o cree que esta propaganda sólo pueden hacerla los Ministros plenipotenciarios y los Cónsules, que hacen vida fácil y no divulgan jamás las cosas del país. Yo creo que puedo hacer lo que ellos no han hecho, por los dos únicos medios de propaganda efectiva: las escuelas y la prensa. Así, pues, mi conciencia me dice que yo no falto en Chile con permanecer lejos algunos años (MISTRAL apud TAGLE DOMÍNGUEZ, 2002, p. 6).

O compromisso com valores que leio na escrita de Mistral é o que me faz pensar os Recados como um tipo de intervenção, visualizando Gabriela Mistral 
como intelectual. Seguindo a leitura de Saítta (2004) sobre os ensaístas argentinos que escreveram depois dos golpes de Estado de 1930 e 1955 e retomando sua análise, para entender o trabalho de Mistral, posso dizer que vejo a autora como uma pessoa que

pensó lo social, otorgó sentidos confiables en momentos de crisis y definió zonas de la sociedad - o de la historia - donde radicaría una verdad nacional ('el espíritu de la tierra', 'el ser nacional', 'el hombre invisible', 'lo nacional y popular') enfrentado a lo falso, lo importado, lo simulado (p. 108-109, ênfase no original).

Nessa ideia de intervenção intelectual, considero que o trabalho de Mistral apresenta um diferencial, o que me permite considerá-lo como fora da norma. Na condição de escritora (mesmo sendo consulesa), teve maior liberdade, ao trabalhar com literatura, pois, além de sua identificação como professora, o que sempre marcou seus compromissos, tinha à disposição recursos estilísticos e literários, algo que não possuía a maioria dos cônsules ou funcionários do governo. Essas liberdades e riquezas deixaram marcas em sua escrita e foram administradas com astúcia, convertendo-se em táticas, no sentido que explicava Michel de Certeau (1994).

Assim, mesmo compartilhando os valores do governo de Pedro Aguirre Cerda, por exemplo, acredito que Mistral exerceu uma liberdade diferente, um tipo de empoderamento, porque, como escritora, nessa resistência,

em vez de reproduzir mecanicamente o esquema das interações onde se insere, dá um salto para uma posição de distância e, deste ângulo, se vê a si mesmo e reconhece e põe em crise os laços apertados que o prendem à teia das instituições (BOSI, 2002, p. 134).

O diferencial que apresenta a escrita de Mistral consiste em que, 
ao contrário da literatura de propaganda - que tem uma única escolha, a de apresentar a mercadoria ou a política oficial sob as espécies da alegoria do bem -, a arte pode escolher tudo quanto a ideologia dominante esquece, evita ou repele (BOSI, 2002, p. 122).

É interessante refletir sobre como Mistral pensou nessas possibilidades que a literatura como tática oferecia para ela, pois, como indicava Bosi (2002), “o espaço da literatura, considerado em geral como o lugar da fantasia, pode ser o lugar da verdade mais exigente" (p. 135). No mesmo sentido, Todorov (1971) dizia que "la literatura existe en tanto que es esfuerzo para decir lo que no dice ni puede decir el lenguaje ordinario; si ella significara lo mismo que el lenguaje ordinario, la literatura no tendría razón de ser" (p. 15).

Seguindo essas leituras, considero que foi na literatura que Mistral encontrou esse espaço aberto de que falava em seu texto Como escribo e a liberdade de considerar a experiência como meio de formação, de atenção, escuta, abertura, disponibilidade, sensibilidade, vulnerabilidade e ex/posição (LARROSA, 2006, p. 108).

\section{CONSIDERAÇÕES FINAIS}

O artigo trabalhou o autoexílio de Gabriela Mistral, como uma experiência que the permitiu criar movimentos compreendidos metaforicamente na figura de danças de roda, entendidas como espaço de resistência, pois, possibilitaram que Mistral resistisse a seu autoexílio, criasse movimentos e uma escrita em coletivo, e se comunicasse com sua comunidade imaginada da América Latina.

A autora escreveu sobre assuntos como a defesa da paz, das liberdades e das democracias, valores com os quais se sentia comprometida e se posicionou em relação às temáticas que afetavam o Chile e a América Latina, defendendo ideias e fazendo circular experiências, informações e modelos. 
Reconhecer a Gabriela Mistral criadora, que nem sempre aparece nas leituras tradicionais, permite também pôr em tensão os modos de racionalidades dominantes que não reconhecem a experiência, a subjetividade, a incerteza, o provisório, o corpo, a fugacidade, a finitude, a vida (LARROSA, 2006, p. 110) todos presentes no seu autoexílio, suas danças de roda, seus Recados e sua forma de educar a sua comunidade imaginada.

Recupero a roda como metáfora para ler a escrita de Mistral, pois foi por meio dessa figura que, sobretudo na última Ditadura chilena, se tentou domesticar e reduzir a escrita mistraliana, apagando suas resistências e criando dela uma imagem passiva. Ressignifico a roda mistraliana para entendê-la como uma mônada onde a autora construiu suas narrações, unindo metaforicamente diferentes vozes; transitou; deslocou-se; dançou e cantou por numerosos espaços simbólicos e também geográficos, nesse autoexílio. Nesse sentido, leio Mistral como intelectual, metaforicamente como um náufrago, figura que nos propõe Said (2005) e que se caracteriza porque

aprende a viver com a terra, não nela; ou seja, não como Robinson Crusoé, cujo objetivo é colonizar sua pequena ilha, mas como Marco Polo, cujo sentido do maravilhoso nunca o abandona e que é um eterno viajante, um hóspede temporário, não um parasita, conquistador ou invasor (p. 67).

Retomando a figura do náufrago, de Said, reconheço Mistral como cantora, como essa pessoa que aprendeu a viver na terra, como uma eterna viajante, como alguém que não perdeu a capacidade de se encantar. Reconheço também a autora como criadora de uma escrita que incluiu diferentes táticas, memórias e tempos, chegando a sonhar com o futuro, pois, segundo Alfredo Bosi (2002), em algumas formas de resistência se encontram a união entre memória e imaginação e até o projeto de utopia voltado ao futuro (p. 130-131).

Cada vez que leio Mistral, fico me perguntando se ainda nos falta ler algumas notas de seus cantos. Temos a sensibilidade para perceber a harmonia e 
as dissonâncias dos cantos da roda mistraliana? Será que conseguimos acompanhar essa Mistral que baila y sueña ${ }^{18}$ ? Toda vez, fico pensando, esperançada, que ainda podemos recolher esse anel de experiências das danças de roda da professora que, no seu autoexílio, criou outras formas de educação a partir das quais pudéssemos construir formas de relacionamento e de existência mais livres e felizes.

Ainda temos tempo de unir nossas mãos e vozes nessas danças de roda para sentir, refletir e circular. Como Mistral (2010f, p. 124) dizia: “iHaremos la ronda infinita!/ iLa iremos al bosque a trenzar,/ la haremos al pie de los montes/y en todas las playas del mar!".

\section{REFERÊNCIAS}

ALMEIDA, Maria Rita Oriolo de. Roda de conversa na educação nãoformal: conflitos e diálogos em busca do encontro para a convivência e o respeito às diferenças. 2011. 210 f. Dissertação (Mestrado em Educação) Programa de Pós-Graduação em Educação, Universidade Estadual de Campinas/Unicamp, Campinas, 2011.

ANDERSON, Benedict. Comunidades imaginadas. Reflexões sobre a origem e a difusão do nacionalismo. São Paulo: Companhia das Letras, 2008.

BENJAMIN, Walter. O narrador. Considerações sobre a obra de Nikolai Leskov. In: BENJAMIN, Walter. Magia e técnica, arte e política. Obras Escolhidas. São Paulo: Brasiliense, 1994. p. 197-221.

BOSI, Alfredo. Narrativa e resistência. In: BOSI, Alfredo. Literatura e Resistência. São Paulo: Companhia das Letras, 2002. p.118-135.

CHAMON Carla Simone; FARIA FILHO, Luciano Mendes de (2007). A educação como problema, a América como destino: a experiência de Maria Guilhermina. In: MIGNOT, Ana Chrystina; GONDRA, José Gonçalves. (org.).

\footnotetext{
${ }_{18}$ Retomo o título de uns dos últimos livros publicados sobre a obra da Gabriela Mistral. Baila y sueña (Dança e sonha) seria uma possibilidade de ouvir esses cantos de roda que começam a circular (VARGAS, 2011).
} 
Viagens pedagógicas. São Paulo: Cortez, 2007. p. 39-64.

DE CERTEAU, Michel. A invenção do cotidiano. Petrópolis: Vozes, 1994. DELEUZE, Gilles; GUATTARI, Félix. Rizoma. Lisboa: Assírio \& Alvim, 2004. DOSSE, François. O desafio biográfico: escrever uma vida. São Paulo: Editora da Universidade de São Paulo, 2009.

DUMOULIÉ, Camille. A capoeira, arte de resistência e estética da potência. In: LINS, Daniel (org). Nietzsche/Deleuze: arte, resistência. Rio de Janeiro: Forense Universitária; Fortaleza: Fundação de Cultura, Esporte e Turismo, 2007.

ELTIT, Diamela. Poeta e intelectual audaz. Los tiempos que marcaron una vida. Revista Patrimonio Cultural, Dibam, Santiago, n. 46, año XIII, p. 30-31, verano 2008.

FALABELLA, Soledad. ¿Qué será de Chile en el cielo? Poema de Chile de Gabriela Mistral. Santiago: LOM Ediciones, 2003.

FALABELLA, Soledad. Desierto: territorio, desplazamiento y nostalgia en Poema de Chile de Gabriela Mistral. Revista Chilena de Literatura, Universidad de Chile, Santiago, n. 50, p. 79-96.

GARCÍA HUIDOBRO, Cecilia. Tarea pendiente: hacerla parte de nuestro imaginario. Revista Patrimonio Cultural, Dibam, Santiago, n. 46, p. 25-25, verano 2008.

GINZBURG, Carlo. Olhos de madeira. Nove reflexões sobre a distância. São Paulo: Companhia das Letras, 2001.

GRANDÓN, Olga. Gabriela Mistral: identidades sexuales, etno-raciales y utópicas. Atenea, Universidad de Concepción, Concepción, n. 500, p. 91-101, II semestre 2009.

GRANDÓN, Olga. La prosa poética de Gabriela Mistral: identidad y discurso. 2004. 119 f. Tesis (Doctorado en Literatura con mención en Literatura Chilena e Hispanoamericana) - Postgrado en Literatura con mención en Literatura Chilena e Hispanoamericana, Universidad de Chile, Santiago, 2004.

LARROSA, Jorge. Sobre la experiencia. Aloma: Revista de Psicologia, Ciències de l'educació i de l'esport, Universitat Ramon Llull, Barcelona, n. 19, p. 87-112, 2006.

LINS, Daniel. Para uma cartografia insubordinada da dança. In: LINS, Daniel 
(org.). Nietzsche e Deleuze: imagem, literatura e educação. Rio de Janeiro: Forense Universitária, 2007.

MANZANO, Rolando. Recorrer la vida desde la vereda contraria. Revista Patrimonio Cultural, Dibam, Santiago, n. 46, p. 10-16, verano 2008.

MISTRAL, Gabriela. Carta a mi biógrafo. El Mercurio, Santiago, 8 de julio de 1934. Disponível em: http://www.bibliotecanacionaldigital.cl/bnd/623/w3article-145631.htm. Acesso em: 27 out. 2018.

MISTRAL, Gabriela. Viajar. In: SCARPA, R. E. (org.). Gabriela anda por el mundo. Santiago: Editorial Andrés Bello, 1978. p. 17-20.

MISTRAL, Gabriela. La bailarina. In: REAL ACADEMIA ESPAÑOLA. Gabriela Mistral en verso y prosa. Antología. Lima: Santillana Ediciones Generales, 2010a. p. 343-345.

MISTRAL, Gabriela. La extranjera. In: REAL ACADEMIA ESPAÑOLA. Gabriela Mistral en verso y prosa. Antología. Lima: Santillana Ediciones Generales, 2010b. p. 283-283.

MISTRAL, Gabriela. Dame la mano. In: REAL ACADEMIA ESPAÑOLA. Gabriela Mistral en verso y prosa. Antología. Lima: Santillana Ediciones Generales, 2010c. p. 124-124.

MISTRAL, Gabriela. Como escribo. In: REAL ACADEMIA ESPAÑOLA. Gabriela Mistral en verso y prosa. Antología. Lima: Santillana Ediciones Generales, 2010d. p. 588-590.

MISTRAL, Gabriela. Recados. In: REAL ACADEMIA ESPAÑOLA. Gabriela Mistral en verso y prosa. Antología. Lima: Santillana Ediciones Generales, 2010e. p. 334-334.

MISTRAL, Gabriela. ¿En dónde tejemos la ronda? In: REAL ACADEMIA ESPAÑOLA. Gabriela Mistral en verso y prosa. Antología. Lima: Santillana Ediciones Generales, 2010f. p. 123-124.

MISTRAL, Gabriela. Ronda de los altos pinares. In: VARGAS SAAVEDRA, Luis (Recopilación). Baila y sueña. Rondas y canciones de cuna inéditas de Gabriela Mistral. Santiago: Ediciones Pontificia Universidad Católica de Chile, 2011a. p. 31-31.

MISTRAL, Gabriela. Niños. In: VARGAS SAAVEDRA, Luis (Recopilación). Baila y sueña. Rondas y canciones de cuna inéditas de Gabriela Mistral. Santiago: Ediciones Pontificia Universidad Católica de Chile, 2011b. p. 24-24. 
MISTRAL, Gabriela. Convite. In: VARGAS SAAVEDRA, Luis (Recopilación). Baila y sueña. Rondas y canciones de cuna inéditas de Gabriela Mistral. Santiago: Ediciones Pontificia Universidad Católica de Chile, 2011c. p. 20-21. MISTRAL, Gabriela. Elquina. In: VARGAS SAAVEDRA, Luis (Recopilación). Baila y sueña. Rondas y canciones de cuna inéditas de Gabriela Mistral. Santiago: Ediciones Pontificia Universidad Católica de Chile, 2011d. p. 23-23.

MISTRAL, Gabriela. Ronda. In: VARGAS SAAVEDRA, Luis (Recopilación). Baila y sueña. Rondas y canciones de cuna inéditas de Gabriela Mistral. Santiago: Ediciones Pontificia Universidad Católica de Chile, 2011e. p. 25-25.

MISTRAL, Gabriela. Canción de zafra II. In: VARGAS SAAVEDRA, Luis (Recopilación). Baila y sueña. Rondas y canciones de cuna inéditas de Gabriela Mistral. Santiago: Ediciones Pontificia Universidad Católica de Chile, 2011f. p. 18-19.

MISTRAL, Gabriela. Ronda del horizonte. In: VARGAS SAAVEDRA, Luis (Recopilación). Baila y sueña. Rondas y canciones de cuna inéditas de Gabriela Mistral. Santiago: Ediciones Pontificia Universidad Católica de Chile, 2011g. p. 34-34.

MISTRAL, Gabriela. Donde bailan los niños. In: VARGAS SAAVEDRA, Luis (Recopilación). Baila y sueña. Rondas y canciones de cuna inéditas de Gabriela Mistral. Santiago: Ediciones Pontificia Universidad Católica de Chile, 2011h. p. 22-22.

OSTRIA GÓNZALEZ, Mauricio. Releyendo Ternura. In: REAL ACADEMIA ESPAÑOLA. Gabriela Mistral en verso y prosa. Antología. Lima: Santillana Ediciones Generales, 2010, p. 649-659.

PIZARRO, Ana. Con identidad transgresora. Referente simbólico de la nación. Revista Patrimonio Cultural, Dibam, Santiago, n. 46, p. 24-24, verano 2008.

SAID, Edward. Fora do lugar: memórias. São Paulo: Companhia das Letras, 2004.

SAID, Edward. Reflexões sobre o exílio e outros ensaios. São Paulo: Companhia das Letras, 2003.

SAID, Edward. Representações do intelectual. São Paulo: Companhia das Letras, 2005.

SAÍTTA, Sylvia. Modos de pensar lo social. Ensayo y sociedad en la Argentina 
(1930-1965). In: NEIBURG, Federico; PLOTKIN, Mariano (org.).

Intelectuales y expertos. La constitución del conocimiento social en la Argentina. Buenos Aires: Paidós, 2004. p.15-30.

SCARPA, Roque Esteban. La desterrada en su patria: Gabriela Mistral en Magallanes. Lisboa; Loures: Editorial Nascimento, 1977.

SCATENA FRANCO, Stella Maris. Peregrinas de outrora, viajantes latino-americanas no século XIX. Florianópolis: Editorial Mulheres; Santa Cruz do Sul: Edunisc, 2008.

SEVCENKO, Nicolau. Literatura como missão. Tensões sociais e criação cultural na Primeira República. São Paulo: Brasiliense, 1983.

TAGLE DOMÍNGUEZ, Matías. Gabriela Mistral y Pedro Aguirre Cerda a través de su correspondencia privada (1919-1941). Historia, PontificiaUniversidad Católica de Chile, Santiago, v. 35, p. 323-408, 2002.

TODOROV, Tzvetan. El hombre desplazado. Madrid: Editorial Taurus, 2008.

TODOROV, Tzvetan. Literatura y significación. Barcelona: Editorial Planeta, 1971.

\section{TRABUCCO VALENZUELA, Sandra. Ternura e o americanismo em}

Gabriela Mistral. 1992. 198 f. Dissertação (Mestrado em Letras) - Programa de Pós-Graduação em Letras, Universidade de São Paulo, São Paulo, 1992.

VALDIVIA DE KIRINUS, Gloria Mercedes. Meia volta - volta e meia: em torno das cantigas de roda de Cecília Meireles e Gabriela Mistral. 1999. $307 \mathrm{f}$. Tese (Doutorado em Letras) - Programa de Pós-Graduação em Teoria Literária e Literatura Comparada, Universidade de São Paulo, São Paulo, 1999.

VARGAS SAAVEDRA, Luis (Comp.). Baila y sueña. Rondas y canciones de cuna inéditas de Gabriela Mistral. Santiago: Ediciones Pontificia Universidad Católica de Chile, 2011.

VON SIMSON, Olga Rodrigues de Moraes. A construção de narrativas orais sugeridas e incentivadas pela visualidade. A conjugação de depoimentos orais e fotografias históricas em pesquisas que visam reconstruir a história do tempo presente (Aguardando publicação pelo Grupo de Pesquisa Memória e Fotografia do Centro de Memória da Universidade Estadual de Campinas, Campinas, Brasil) (no prelo). 
CAROLA GABRIELA SEPÚLVEDA VÁSQUEZ é Professora Associada da Universidad Metropolitana de Ciencias de la Educación (UMCE - Chile). Doutora em Educação pela Universidade Estadual de Campinas (Unicamp) - Área de Concentração em Ciências Sociais na Educação - com bolsa da Comisión Nacional de Investigación Científica y Tecnológica - Gobierno de Chile, Mestra em Estudos de Gênero e Cultura pela Universidad de Chile - Menção em Humanidades - e Bacharel e Licenciada em História e Geografia pela Universidad de Santiago de Chile.

E-mail: carolasepulvedavasquez@gmail.com

(D) http://orcid.org/0000-0003-4772-3719

Recebido em: 21 de março de 2020

Aprovado em: 29 de junho de 2020

Editora responsável: Dóris Almeida

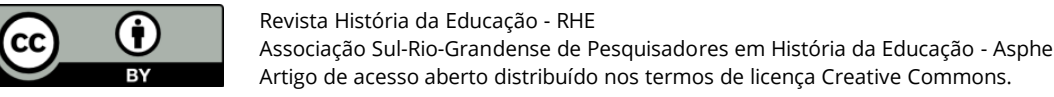

